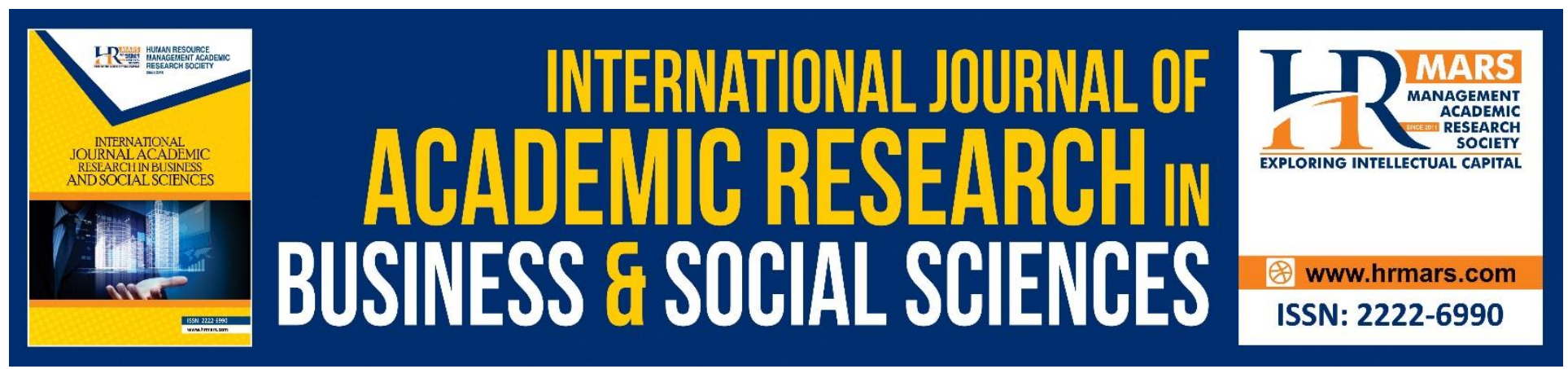

\title{
How do Personality Factors Associate with Prosocial Behavior? The Mediating Role of Empathy
}

Alsalman Arwa Abdullah, Hanina H. Hamsan, and Aini Azeqa Ma'rof

To Link this Article: http://dx.doi.org/10.6007/IJARBSS/v10-i16/8303

DOI:10.6007/IJARBSS/v10-i16/8303

Received: 01 October 2020, Revised: 17 October 2020, Accepted: 15 November 2020

Published Online: 30 November 2020

In-Text Citation: (Abdullah et al., 2020)

To Cite this Article: Abdullah, A. A., Hamsan, H. H., \& Ma'rof, A. A. (2020). How do Personality Factors Associate with Prosocial Behavior? The Mediating Role of Empathy. International Journal of Academic Research in Business and Social Sciences, 10(16), 206-219.

Copyright: (C) 2020 The Author(s)

Published by Human Resource Management Academic Research Society (www.hrmars.com)

This article is published under the Creative Commons Attribution (CC BY 4.0) license. Anyone may reproduce, distribute, translate and create derivative works of this article (for both commercial and non-commercial purposes), subject to full attribution to the original publication and authors. The full terms of this license may be seen at: $\underline{\text { http://creativecommons.org/licences/by/4.0/legalcode }}$

Special Issue: Youth and Community Wellbeing: Issues, Challenges and Opportunities for Empowerment V2, 2020 , Pg. 206 - 219

Full Terms \& Conditions of access and use can be found at http://hrmars.com/index.php/pages/detail/publication-ethics 


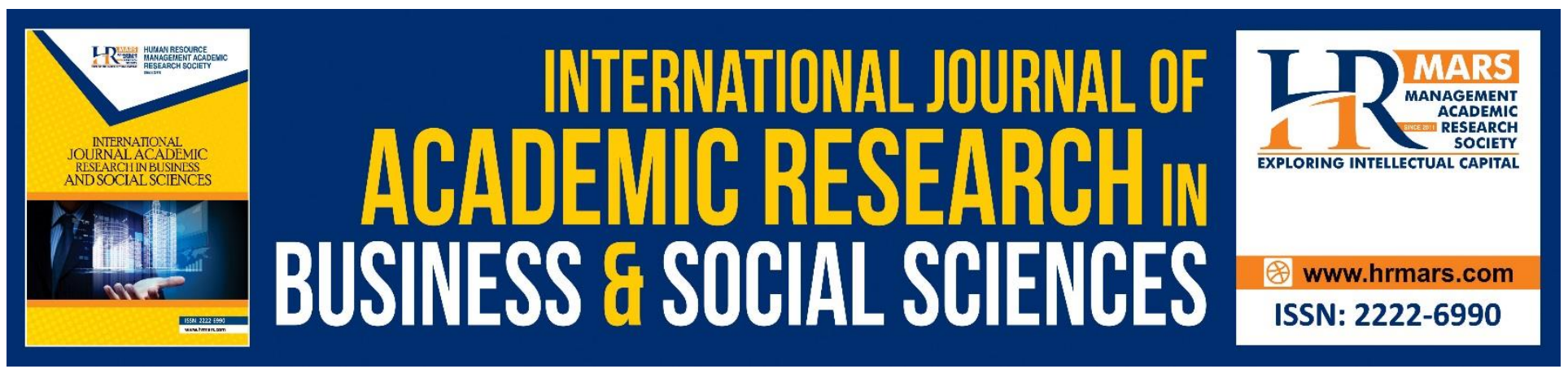

\title{
How do Personality Factors Associate with Prosocial Behavior? The Mediating Role of Empathy
}

\author{
${ }^{2}$ Alsalman Arwa Abdullah, ${ }^{1,2}$ Hanina H. Hamsan, and ${ }^{1,}$ \\ ${ }^{2}$ Aini Azeqa Ma'rof
}

${ }^{1}$ Institute for Social Science Studies, Putra Infoport, Universiti Putra Malaysia, 43400 UPM Serdang, Selangor, Malaysia, ${ }^{2}$ Faculty of Human Ecology Manusia, Universiti Putra Malaysia,43400 UPM

Serdang, Selangor Darul Ehsan, Malaysia

Email: hanina@upm.edu.my, aaab97@gmail.com, azeqa@upm.edu.my

\begin{abstract}
This research aims to examine the relationships between empathy, prosocial behaviour, and personality factors among Saudi undergraduate students. In total, 394 Saudi undergraduates participated in the study, which employed the prosocial behaviour scale (PBC), international personality item pool (IPIP), and Toronto empathy questionnaire (TEQ). The Pearson correlation analysis was used to investigate the associations between the research variables, while process macro analysis used to examine whether empathy mediates the association between agreeableness and prosocial behaviour. The research findings indicate that personality factors are related to empathy. Saudi undergraduates who show higher degrees of empathy would also show high degrees of prosocial behaviours. In addition, personality factors were similarly associated with prosocial behaviour. The results also show that empathy mediates the relationship between prosocial behaviour and agreeableness. The results of this study expand the existing literature review on prosocial behaviour by explaining how personality factors influence prosocial behaviour through the mediation role of empathy.
\end{abstract}

Keywords: Prosocial Behavior, Personality Factors, Empathy, Undergraduates.

\section{Introduction}

Prosocial behaviour is one of the most considerable types of positive behaviour that promote social relationships (Fabes, Carlo, Kupanoff, \& Laible, 1999). It is a useful behaviour directed at others too (Eisenberg \& Miller, 1987). This positive behaviour is a broad, multi-component structure comprising assistance, participation, cooperation, and donation (Fabes \& Eisenberg, 1998). However, young people tend to live in a selfish environment in which they seek personal accomplishments and ignore others (Finkelstein, 2010). Studies have revealed the low level of prosocial behaviour among young people, which is an indicator that may have severe consequences on their behaviour (Caprara, \& 
Pastorelli, 1993). A decrease in this behaviour can have negative effects on the personal and social levels (Carlo et al., 2014). Individuals who have a low level of prosocial behaviour can have weak social skills (Stormshak, Bierman, Bruschi, Dodge, \& Coie, 1999). According to McDonald, Wang, Menzer, Rubin, and Booth-LaForce (2011), the low prosocial behaviour leads to an imbalance in social relations. The lowering of the level of prosocial behaviour amongst the youth increases their level of violence and aggression (McMahon et al, 2013). It may even be an indication of crimes (Hamalainen \& Pulkkinen, 1995). Therefore, it is important to consider carefully the steps for raising the level of prosocial behaviour.

In the past few decades, psychologists have examined the determinants of prosocial behaviour and the factors that influence it (Grant and Mayer, 2009). Prosocial behaviour is a challenging field of study, as it is difficult to understand why individuals participate in behaviours that are beneficial to others and what costs an individual who performs positive behaviour has to bear, especially because in some cases individuals may put their lives at risk to help others (Penner, Dovidio, Piliavin, \& Schroeder, 2005). Psychologists propose various reasons why people engage in prosocial behaviour (Batson \& Powell, 2003). Research has identified the major role of empathy in prosocial behaviour (Eisenberg, \& Miller, 1987; Eisenberg et al., 1991; Roberts, \& Strayer, 1996). Other research has revealed the significant role that personality factors (extraversion, neuroticism, conscientiousness, agreeableness, and openness) play in prosocial behaviour. Every factor of personality has considerable impact on behavior (Batson, 1987; Ma, Shek, Cheung, \& Lee, 1996; Pisheh et al., 2014). In the context, this study focuses on examining the factors that play an effective role in prosocial behaviour.

\section{Literature Review}

\section{Personality Factors and Prosocial Behaviour}

Personality factors (extraversion, neuroticism, conscientiousness, agreeableness, and openness) influence various elements including prosocial behaviour (Thielmann, Spadaro, \& Balliet, 2020). Personality factors are internal factors that affect thinking and emotion, which lead individuals to act pro-socially (Shah \& Rizvi, 2016). In fact, research has already found that personality factors influence prosocial behaviour positively (Brown and Taylor, 2015). Afolabi (2013) studied factors that influence prosocial behaviour among 358 undergraduate students in Nigeria and found that all personality factors are related to prosocial behaviour and that conscientiousness has a great influence on the behaviour of university students. In another study, Hilbig, Glockner, and Zettler (2014) found that students with a high level of agreeableness are more involved in prosocial behaviour and are more helpful to others. Kline, Bankert, Levitan, and Kraft (2019) also observed that agreeableness and openness are related to prosocial behaviour. Agreeable individuals have good relationships with others and they seek to help others in need. Conversely, personality factors may negatively affect prosocial behaviour too. According to Guo, Sun, and Li (2018), neuroticism limits the level of prosocial behaviour. Researchers also explained that the neurotic individuals are less empathetic, which leads them to not care for or respond to the needy and those around them. 


\section{Personality Factors and Empathy}

Personality factors are not only related to prosocial behaviour but also are associated with empathy. Personality is considered as a set of traits that influence empathy (Decety, 2011) .According to De Aguiar, Formiga, and Cantinilo (2017 )personality factors contribute to the level of empathy. Agreeableness, extraversion, conscientiousness, and openness increase the level of empathy. However, neuroticisms reduce the level of empathy. Likewise, Song and Sh (2017) noted that Chinese medical students are characterised by a high level of agreeableness and openness, conscientiousness, and neuroticisms which in turn contribute to influence their empathy positively or negative.In line with this,Melchers, Li, Haas, and Reuter (2016) reported that individuals with agreeableness, conscientiousness, and openness are more likely to empathize others in need .Karmakar, Chatterjee, and Dogra (2017) found that agreeableness enhances individual feelings and raises the level of empathy. Personality factors, especially agreeableness, play a crucial role in improving the empathy of university students (Costa, Alves, Neto, Marvao, Portela, \& Costa, 2014).

\section{Empathy and Prosocial Behaviour}

According to Telle and Pfister (2015), empathy is an internal factor and is closely related to prosocial behaviour. Davis and Franzoi (1991) indicated that empathy is a personal skill that links individuals with the outside world and allows them to understand the painful feelings of others and help them. Evidence indicates that empathy is an essential component that stimulates prosocial behaviour and a high degree of empathy leads to a trend towards prosocial behaviour (Hoffman, 2008). Similarly, Sze, Gyurak, Goodkind, and Levenson (2012) explored the associations between empathy and prosocial behaviour by watching a film depicting the needy individuals. The researchers found that sad scenes stimulate empathy and predict greater prosocial behaviour in the future. Taylor, Eisenberg, Spinrad, Eggum, and Sulik (2013) reported that empathy is the main element behind the occurrence of prosocial behaviour. Individuals' high empathy predicts more prosocial behaviour in the future. Johnson (2012) conducted two studies. He noted in the first study that fairy tales contribute to improving the empathy of the participants. In the second study, the individuals who participated in the first study showed a high prosocial behaviour compared to those who did not participate in the first study. According to Lockwood, Seara-Cardoso, and Viding (2014), empathy is an emotional and psychological indicator that can dramatically raise the level of prosocial behaviour. Across the decades, investigation and modelling of the relationship between prosocial behaviour and empathy has led to consideration of the latter as a great motivator as well as determining factor in the incidence of prosocial behaviour (Gordon, 2014).

Based on the existing literature on empathy, prosocial behaviour, and personality factors, it was established that all variables relate to one another. However, their common relationships are not well understood. Theoretically, the empathy-altruism hypothesis mentioned that empathy has a key role in prosocial behaviour (Batson et al., 1988). This hypothesis explains why empathy, when influenced by certain personality factors and in particular, agreeableness, will lead to prosocial behaviour. Hence, the aim of this research is to explain these associations more clearly, in terms of the role of empathy in mediating the relationship between prosocial behaviour and agreeableness. 


\section{Objectives of the Study}

This study aims to investigate the relationship between empathy, prosocial behaviour, and personality factors. Furthermore, its other objective is to determine if empathy has a mediating role in the relationship between personality factors and prosocial behaviour.

\section{Hypotheses of the Study}

$\mathrm{H}_{1}$ : Personality factors would be related to prosocial behaviour.

$\mathrm{H}_{2}$ : Personality factors would be related to empathy.

$\mathrm{H}_{3}$ : Empathy would be positively associated with prosocial behaviour.

$\mathrm{H}_{4}$ : Empathy would mediate the association between agreeableness and prosocial behaviour.

\section{Methodology}

This section presents the participants, measurement, and data analysis for this study.

\section{Participant}

The researchers collected the data from a sample of 394 undergraduates across three universities in Riyadh, Saudi Arabia in December 2019. The sample included 178 (45.2\%) male and 216 (54.8\%) female; more than 26\% respondents were 21 years old and $25.6 \% 20$ years old. Most respondents were from King Saud University (54.8\%), followed by Imam Muhammad bin Saud University (32.7\%), $12.5 \%$ of the respondents were from Majmaah University.

\section{Measurement}

The researchers have used the prosocial behaviour scale prepared by Cabrara et al. (2005) to measure the prosocial of individuals. The items refer to the tendency involved in prosocial behaviour such as cooperation and helping behaviour towards others. The scale includes 16 phrases, and these phrases are in a positive direction. This questionnaire was followed by a five-point Likert scale for indicating whether the statement was: never, rarely, sometimes, always, or permanently (Caprara et al., 2005). The overall score refers to an individual's participation in prosocial behaviour. The higher scores on this questionnaire indicate a high level of prosocial behaviour. In this research, the scale was shown to be highly reliable using the alpha-Cronbach coefficients (0.933).

Personality factors: To examine students' personality factors, the international personality item pool (IPIP) is used (Goldberge, Johnson, Eber, Hogan, Ashton, Cloninger \& ,Gough, 2006). This questionnaire follows the five-factor model. It consists of 50 items that depict the importance of 5 personality factors (neuroticism, extraversion, conscientiousness, agreeableness, and openness). Each type of personality has 10 items and every phrase is based on the 5-point Likert scale "very inaccurate, moderately inaccurate, neutral, moderately accurate, very accurate" with a value of 1 to 5 , ranging from very inaccurate to very accurate. The Cronbach Alpha of personality factors is as follows: neuroticisms 0.832 , extraversion 0.911 , agreeableness 0.851 , conscientiousness 0.871 , and openness 0.870 , which means that all personality factors had acceptable reliability.

Empathy: The Toronto empathy questionnaire was utilised to measure undergraduates' empathy. This scale consists of sixteen items that contain positive statements that are $1,3,5,6,8,9,13,16$. It 
also embraces reverse elements which are $2,4,7,10,11,12,14,15$. The measurement of the phrases are never $=0$; Rarely $=1$; Sometimes $=2$; Often $=3$; Always $=4$ (Spreng et al., 2009). Indeed, the reliability of the empathy questionnaire is $(0.917)$ which indicates a high reliability.

\section{Data analysis}

SPSS was utilized to analyse the data. Pearson correlation was applied to investigate the relationship between empathy, prosocial behaviour, and personality factors. Besides, process macro was used to ascertain whether there is mediation for empathy in the relation between agreeableness and positive behaviour.

\section{Results/Findings}

This study was hypothesised that conscientiousness, extraversion, openness, and agreeableness are positively associated with prosocial behaviour, whereas neuroticism is negatively associated with prosocial behaviour. Table 1 shows that all personality factors had relationships with prosocial behaviour. Extraversion ( $r=0.109, p<.05)$, conscientiousness $(r=0.260, p<.01)$, agreeableness $(r=$ $0.475, p<.01)$, and openness $(r=0.162, p<.01)$ were positively associated with prosocial behaviour. Thus, $\mathrm{H}_{1 a}$ supported. Moreover, a neuroticism $(r=-.89, p<.05)$ was negatively related to prosocial behaviour. Hence, $\mathrm{H}_{1 \mathrm{a}}$ and $\mathrm{H}_{1 b}$ was supported.

Table 1: The association between Personality Factors, Empathy, and Prosocial behavior

\begin{tabular}{lcccc}
\hline Personality Factors & \multicolumn{2}{c}{ Empathy } & \multicolumn{2}{c}{ Prosocial behavior } \\
\cline { 2 - 5 } & Coefficient & Sig. & Coefficient & Sig. \\
\hline Extraversion & .077 & .064 & .109 & .015 \\
Neuroticism & -.005 & .458 & -.089 & .039 \\
Conscientiousness & .109 & .015 & .260 & .000 \\
Agreeableness & .424 & .000 & .475 & .000 \\
Openness & .172 & .000 & .162 & .001 \\
\hline
\end{tabular}

Note. Correlation is significant at the 0.05 level (2-tailed).

The results indicated that undergraduates who had extroversion, agreeableness, conscientiousness, and openness were found involved in prosocial behaviour activities. Meanwhile, an increase in neuroticism limits the prosocial behaviour of undergraduates.

Table 1 also shows that conscientiousness $(r=0.109, p<.01)$, agreeableness $(r=424, p<01)$, and openness $(r=0.172, p<.01)$ were positively related to empathy. But there is no association between extraversion and empathy. $\mathrm{H}_{\mathrm{a} 2}$ is partly supported. Neuroticism did not correlate with empathy, and thus $\mathrm{H}_{2 b}$ is rejected. The relationships imply that higher degrees of conscientiousness, openness, and agreeableness lead to higher degrees of empathy.

$\mathrm{H}_{3}$ is hypothesised:

Empathy is positively associated with prosocial behaviour. 
Table 2: Correlation between Empathy and Prosocial Behavior

\begin{tabular}{ccc} 
& \multicolumn{2}{c}{ Prosocial behavior } \\
\cline { 2 - 3 } & Coefficient & Sig. \\
\hline Empathy & .394 & .000 \\
\hline
\end{tabular}

Note. Correlation is significant at the 0.05 level (2-tailed).

Table 2 shows that empathy is positively associated with prosocial behaviour $(r=0.394 ; p<.01)$. It was also found that undergraduates with a high level of empathy had a high level of prosocial behaviour. Therefore, $\mathrm{H}_{3}$ is supported.

$\mathrm{H} 4$ hypothesises that empathy mediates the association between agreeableness and prosocial behaviour.

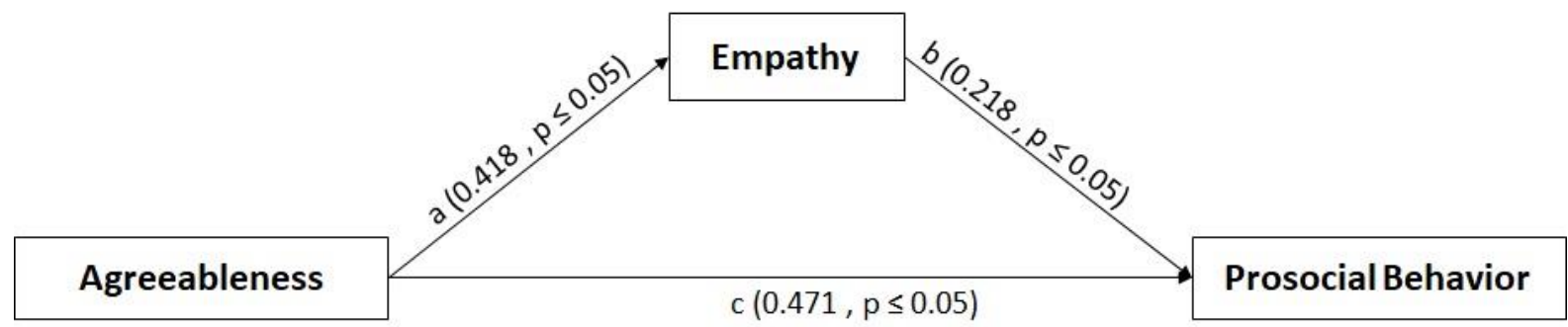

Figure 1: Association between Agreeableness and Prosocial Behavior Mediated through Empathy

Figure 1 show that the direct association between agreeableness and empathy was noted where agreeableness positively predicted empathy $(B=.418, \mathrm{SE}=.045, p<.05)$. Moreover, agreeableness $(B=.471, \mathrm{SE}=.057, p<.05)$ and empathy $(B=.218, \mathrm{SE}=.058, p<.05)$ positively predicted prosocial behaviour. In addition, the indirect coefficient was similarly established as significant $(B=0.091, \mathrm{SE}=$ 0.030 at the $95 \%$ interval level, upper level confidence interval $(\mathrm{ULCl})=0.1540$ and lower level confidence interval $(\mathrm{LLCl})=0.0349)$. Subsequently, $\mathrm{H} 4$ is supported. This finding suggests that empathy mediates the association between prosocial behaviour and agreeableness.

\section{Discussion}

The aim of this research is to investigate the relationship between empathy, prosocial behaviour, and personality factors. Furthermore, this study aims to examine the role of empathy in mediating the relationship between prosocial behaviour and agreeableness. Firstly, it was first established that associations are present among all research variables regarding Saudi undergraduates. Secondly, analysis of the correlations between empathy, agreeableness, and prosocial behaviour recognised the mediating influence of empathy between both variables.

The findings of this study report that undergraduates who had extraversion, agreeableness, conscientiousness, and openness were more actively prosocial which corresponds to (Pursell et al., 2008; Kanacri et al., 2014). The results also show that neurotic undergraduates had low level of prosocial behaviour. Indeed, neuroticism leads to a decrease in the involvement in prosocial behaviour activity and that agree with (Chaparro \& Grusec, 2016). In fact, these findings support the 
Five Factors Model that explains the extent to which personality factors are related to behavior, and that each factor has a distinct and unique effect on prosocial behavior (Caprara et al., 2012). According to this fact, the agreeable has an interest in the feelings of the needy and thus seeks to share and help them. In addition, the individual who hold openness tends to participate in new actions, as he believes that his involvement in prosocial behaviors such as volunteer work is kind of the new experience that contributes to self-realization. Further, conscience individual considers prosocial behavior as one of the duties and tasks that could be provide towards their societies and requires to be aware of others. It also indicates that the extroverted tends to participate in the social activities, particularly that he is a social person (Muetia, 2016). On the contrary, a neurotic has negative feelings towards others, which hinders his progress in all positive behaviors including prosocial behavior (Koffi, 2020).

In this research, it was also noted that undergraduates who hold agreeableness, conscientiousness, and openness had also high level of empathy. These findings support a considerable portion of previous studies on the association between personality factors and empathy (Decety, 2011). For instance, Melchers, et al. (2016) noted that agreeableness, openness, and conscientiousness are the most significant factors that lead to rising empathy. However, the findings of this study partly supported De Aguiar, et al. (2017); Song and Shi (2017) who reported that extravert, agreeable, conscious, and openness individuals are more empathetic compared to neurotic people. Although the report indicated that there are statistically significant effects of some of the five factors on empathy, it points out that further investigation into these issues could help researchers improve students' empathy towards the issues of their society.

Based on the study objectives, the association between prosocial behaviour and empathy was examined. Research has shown empathy to be positively associated with prosocial behaviour, wherein undergraduates who showed higher degrees of empathy would act pro-socially. The research findings align with that of past studies in this area, wherein empathy plays a key pivot role as regards prosocial behaviour (Deschamps, Schutter, Kenemans \& Matthys, 2015; Majdandzic, Amashaufer, Hummer, Windischberger, \& Lamm, 2016). Based on Telle \& Pfister (2016), empathy leads individuals to share feelings that contribute towards getting involved in prosocial behaviour. Davis (2015) considered empathy as an internal driver and a major determinant of whether a person will help others. Indeed, psychologists indicate that empathy plays a crucial and major role in prosociality.

The findings of this research showed that there are significant associations between personality factors, empathy, and prosocial behaviour. These findings reinforce the results of the previous research. However, these relationships do not offer a clear understanding of how these elements are related to each other. It was therefore useful to examine the mediating influence of empathy in the relationship between prosocial behaviour and agreeableness. In this study, it was hypothesised that agreeableness influences the prosocial behaviours of undergraduates, whereas the relationship between prosocial behaviour and agreeableness is supposedly mediated by empathy. Research results appear to show that the relationship between prosocial behaviour and agreeableness is 
mediated by empathy. The findings suggest that agreeableness has a direct influence on the empathy of Saudi undergraduates. According to Graziano, Habashi, Sheese, \& Tobin, (2007), agreeableness heightens the degree of empathy. Butrus \& Witenberg (2013) reported that the youth who are agreeable express their emotions, especially their empathy, towards others. Agreeableness was similarly established as a meaningful predictor of empathy among Saudi undergraduates, as well as a positive indicator of their prosocial behaviour. In this research, it was established that agreeableness and empathy both have indirect effects on prosocial behaviour and that the influences point to the considerable mediating role of empathy. Hypothetically, the empathy-altruism model states that agreeable persons are more empathetic, which leads to such individuals being more involved in prosocial behaviour. Prosocial behaviour will not occur unless the person who has an agreeableness personality shows empathy (Batson, \& Powell, 2003). According to Batson (2010), individuals who have an agreeableness personality understand the situation of the needy, and this touches their empathy and thus they are looking for ways to help them.

Despite several studies investigating the associations between personality, empathy, and prosocial behaviour separately, no research has yet investigated these correlations at the same time. The primary objective of this study is to determine whether empathy has a mediating role in the relationship between prosocial behaviour and agreeableness. We believe that our analysis of mediation contributes to deeper understanding of how personality factors relate to prosocial behaviour and empathy.

\section{Conclusion}

This research emphasises the importance of empathy and personality factors regarding prosocial behaviour among Saudi undergraduates. The results of this study offer support for future research through the combined effect of agreeableness and empathy to improve the prosocial behaviour. This study finds that students who had agreeableness were also more empathetic and that contributed significantly to their participation in prosocial behaviour. Therefore, the results of this research have implications for university officials and faculty members in terms of directing students according to their type personalities and empathy and engaging in prosocial behaviour, which contributes to promoting prosocial behaviour among students. Students should recognise their personalities and emotions and the officials and faculty should lead them in a positive direction to help develop their prosocial behaviour.

\section{Limitation and Study Forward}

Future research might address the limitations of this study. First, the sample of this study comprised undergraduate students, and hence the results may not apply to other age groups. Future researchers should study the factors of personality, empathy, and prosocial behaviour on children, adolescents, and the elderly. Second, the result of this study can be attributed to a specific geographical area or the tools used. Expansions of study area and tools may give more general results. Lastly, the influence of personality factors on prosocial behaviour may vary through the mediating role of empathy. In such case, it is proposed that evaluations of other personality factors be included in the analysis of 
mediation, especially as this research only examined the mediating role of empathy in correlations between prosocial behaviour and agreeableness.

\section{References}

Afolabi, O. A. (2013). Roles of personality types, emotional intelligence, and gender differences in prosocial behavior. Psychological Thought, 6(1), 124-139.

http://dx.doi.org/10.23668/psycharchives.1918

Batson, C. D., Dyck, J. L., Brandt, J. R., Batson, J. G., Powell, A. L., McMaster, M. R., \& Griffitt, C. (1988). Five studies testing two new egoistic alternatives to the empathy-altruism hypothesis. Journal of Personality and Social Psychology, 55(1), 52-77. https://doi.org/10.1037/0022-3514.55.1.52

Batson, C. D. (1987). Prosocial motivation: Is it ever truly altruistic. In Advances in experimental social psychology (Vol. 20, pp. 65-122). Academic Press. https://doi.org/10.1016/S0065-2601(08)60412-8

Batson, C. D., Batson, J. G., Slingsby, J. K., Harrell, K. L., Peekna, H. M., \& Todd, R. M. (1991). Empathic joy and the empathy-altruism hypothesis. Journal of Personality and Social Psychology, 61(3), 413-426. https://doi.org/10.1037/0022-3514.61.3.413

Batson, C. D., \& Powell, A. A. (2003). Altruism and prosocial behavior. Handbook of psychology, 463484. https://doi.org/10.1002/0471264385.wei0519

Batson, C. D. (2010). Empathy-induced altruistic motivation. In M. Mikulincer \& P. R. Shaver (Eds.), Prosocial motives, emotions, and behavior: The better angels of our nature (p. 15-34). American Psychological Association. https://doi.org/10.1037/12061-001

Bierhoff, H. W., \& Rohmann, E. (2004). Altruistic personality in the context of the empathy-altruism hypothesis. European Journal of Personality, 18(4), 351-365. https://doi.org/10.1002/per.523

Brown, S., \& Taylor, K. (2015). Charitable behaviour and the big five personality traits: Evidence from UK panel data. Sheffield economic paper research series (pp. 30). IZA Discussion Paper No. 9318.

https://ssrn.com/abstract $=2656503$

Butrus, N., \& Witenberg, R. T. (2013). Some personality predictors of tolerance to human diversity: The roles of openness, agreeableness, and empathy. Australian Psychologist, 48(4), 290-298. https://doi.org/10.1111/j.1742-9544.2012.00081.x

Caprara, G. V., \& Pastorelli, C. (1993). Early emotional instability, prosocial behaviour, and aggression: Some methodological aspects. European Journal of personality, 7(1), 19-36. https://doi.org/10.1002/per.2410070103

Caprara, G. V., Steca, P., Zelli, A., \& Capanna, C. (2005). A new scale for measuring adults' prosocialness. European Journal of Psychological Assessment, 21(2), 77-89. doi:10.1027/10155759.21.2.77 
Carlo, G., Mestre, M. V., McGinley, M. M., Tur-Porcar, A., Samper, P., \& Opal, D. (2014). The protective role of prosocial behaviors on antisocial behaviors: The mediating effects of deviant peer affiliation. Journal of Adolescence, 37(4), 359-366.

https://doi.org/10.1016/j.adolescence.2014.02.009

Chaparro, M. P., \& Grusec, J. E. (2016). Neuroticism moderates the relation between parenting and empathy and between empathy and prosocial behavior. Merrill-Palmer Quarterly (1982), 62(2), 105-128.

DOI: 10.13110/merrpalmquar1982.62.2.0105

Costa, P., Alves, R., Neto, I., Marvao, P., Portela, M., \& Costa, M. J. (2014). Associations between medical student empathy and personality: a multi-institutional study. PloS one, 9(3), e89254. https://doi.org/10.1371/journal.pone.0089254

Davis, M. H. (2015). Empathy and prosocial behavior. In D. A. Schroeder \& W. G. Graziano (Eds.), Oxford library of psychology. The Oxford handbook of prosocial behavior (p. 282-306). Oxford University Press. https://doi.org/10.1093/oxfordhb/9780195399813.013.026

Davis, M. H., \& Franzoi, S. L. (1991). Stability and change in adolescent self-conscientiousness and empathy. Journal of research in Personality, 25(1), 70-87. https://doi.org/10.1016/0092-6566(91)90006-C

De Aguiar, C. S., Formiga, N. S., \& Cantinilo, A. (2017). Personality traits and empathic abilities: A predictive study on medical students. Boletim Academia Paulista de Psicologia, 37(92), 129138.

Decety, J. (2011). The neuroevolution of empathy. Annals of the New York Academy of Sciences, $1231(1), 35-45$.

Doi: 10.1111/j.1749-6632.2011.06027.x.

Deschamps, P. K. H., Schutter, D. J. L. G., Kenemans, J. L., \& Matthys, W. (2015). Empathy and prosocial behavior in response to sadness and distress in 6-to 7-year olds diagnosed with disruptive behavior disorder and attention-deficit hyperactivity disorder. European child \& adolescent psychiatry, 24(1), 105-113.

https://doi.org/10.1007/s00787-014-0535-x

Eisenberg, N., \& Miller, P. A. (1987). The relation of empathy to prosocial and related behaviors. Psychological Bulletin, 101(1), 91-119. https://doi.org/10.1037/0033-2909.101.1.91

Eisenberg, N., Miller, P. A., Shell, R., McNalley, S., \& Shea, C. (1991). Prosocial development in adolescence: A longitudinal study. Developmental Psychology, 27(5), 849-857. https://doi.org/10.1037/0012-1649.27.5.849

Fabes, R. A., \& Eisenberg, N. (1998). Meta-analyses of age and sex differences in children's and adolescents' prosocial behavior. Handbook of child psychology, 3, 1-29.

Fabes, R. A., Carlo, G., Kupanoff, K., \& Laible, D. (1999). Early adolescence and prosocial/moral behavior I: The role of individual processes. The Journal of Early Adolescence, 19(1), 5-16. https://doi.org/10.1177/0272431699019001001

Finkelstein, M. A. (2010). Individualism/collectivism: Implications for the volunteer process. Social Behavior and Personality: An international journal, 38(4), 445-452. 
https://doi.org/10.2224/sbp.2010.38.4.445

Goldberg, L. R., Johnson, J. A., Eber, H. W., Hogan, R., Ashton, M. C., Cloninger, C. R., \& Gough, H. G. (2006). The international personality item pool and the future of public-domain personality measures. Journal of Research in Personality, 40(1), 84-96.

https://doi.org/10.1016/j.jrp.2005.08.007

Gordon, H. (2014). Investigating the relation between empathy and prosocial behavior: An emotion regulation framework (Doctoral dissertation, Virginia Tech).

http://hdl.handle.net/10919/78070

Grant, A. M., \& Mayer, D. M. (2009). Good soldiers and good actors: Prosocial and impression management motives as interactive predictors of affiliative citizenship behaviors. Journal of Applied Psychology, 94(4), 900-912. https://doi.org/10.1037/a0013770

Graziano, W. G., Habashi, M. M., Sheese, B. E., \& Tobin, R. M. (2007). Agreeableness, empathy, and helping: A person $\times$ situation perspective. Journal of Personality and Social Psychology, 93(4), 583-599.

https://doi.org/10.1037/0022-3514.93.4.583

Guo, Q., Sun, P., \& Li, L. (2018). Why neurotic individuals are less prosocial? A multiple mediation analysis regarding related mechanisms. Personality and Individual Differences, 128, 55-61. https://doi.org/10.1016/j.paid.2018.02.026

Hamalainen, M., \& Pulkkinen, L. (1995). Aggressive and non-prosocial behaviour as precursors of criminality. Studies on Crime \& Crime Prevention, 4(1), 6-21.

Hilbig, B. E., Glockner, A., \& Zettler, I. (2014). Personality and prosocial behavior: Linking basic traits and social value orientations. Journal of Personality and Social Psychology, 107(3), 529-539. https://doi.org/10.1037/a0036074

Hoffman, M. L. (2008). Empathy and prosocial behavior. Handbook of emotions, 3, 440-455.

Johnson, D. R. (2012). Transportation into a story increases empathy, prosocial behavior, and perceptual bias toward fearful expressions. Personality and individual differences, 52(2), 150155. https://doi.org/10.1016/j.paid.2011.10.005

Kanacri, B. P. L., Pastorelli, C., Eisenberg, N., Zuffianò, A., Castellani, V., \& Caprara, G. V. (2014). Trajectories of prosocial behavior from adolescence to early adulthood: Associations with personality change. Journal of adolescence, 37(5), 701-713. https://doi.org/10.1016/j.adolescence.2014.03.013

Karmakar, A., Chatterjee, P., \& Dogra, A. K. (2017). Does relationship between agreeableness and empathy vary considering other personality factors? An empirical study. Indian Journal of Health and Wellbeing, 8(8), 826-831. http://www.iahrw.com/index.php/home/journal_detail/19\#list

Kline, R., Bankert, A., Levitan, L., \& Kraft, P. (2019). Personality and prosocial behavior: A multilevel meta-analysis. Political Science Research and Methods, 7(1), 125.

DOI: https://doi.org/10.1017/psrm.2017.14

Koffi, B. J. (2020). Inferring Big Five Personality Factors using Text Analysis Its Assessment and Impact on Prosocial Behavior and IS Security Compliance (Unpublished doctoral dissertation). The University of Texas at Arlington. 
Retrieved from http://hdl.handle.net/10106/29116

Kwon, S. J. (2018). A relationship between personality and empathy in teenagers' school sports club participation. Journal of exercise rehabilitation, 14(5), 746. https://www.ncbi.nlm.nih.gov/pmc/articles/PMC6222162/

Lockwood, P. L., Seara-Cardoso, A., \& Viding, E. (2014). Emotion regulation moderates the association between empathy and prosocial behavior. PloS one, 9(5), e96555. https://doi.org/10.1371/journal.pone.0096555

Ma, H. K., Shek, D. T., Cheung, P. C., \& Lee, R. Y. (1996). The relation of prosocial and antisocial behavior to personality and peer relationships of Hong Kong Chinese adolescents. The Journal of Genetic Psychology, 157(3), 255-266.

https://doi.org/10.1080/00221325.1996.9914863

Magalhaes, E., Costa, P., \& Costa, M. J. (2012). Empathy of medical students and personality: evidence from the Five-Factor Model. Medical Teacher, 34(10), 807-812. https://doi.org/10.3109/0142159X.2012.702248

Majdandzic, J., Amashaufer, S., Hummer, A., Windischberger, C., \& Lamm, C. (2016). The selfless mind: How prefrontal involvement in mentalizing with similar and dissimilar others shapes empathy and prosocial behavior. Cognition, 157, 24-38. https://doi.org/10.1016/j.cognition.2016.08.003

McDonald, K. L., Wang, J., Menzer, M. M., Rubin, K. H., \& Booth-LaForce, C. (2011). Prosocial behavior moderates the effects of aggression on young adolescents' friendships. International Journal of Developmental Science, 5(1-2), 127-137.

DOI: 10.3233/DEV-2011-10066

McMahon, S. D., Todd, N. R., Martinez, A., Coker, C., Sheu, C. F., Washburn, J., \& Shah, S. (2013). Aggressive and prosocial behavior: Community violence, cognitive, and behavioral predictors among urban African American youth. American Journal of Community Psychology, 51(3-4), 407-421. https://doi.org/10.1007/s10464-012-9560-4

Melchers, M. C., Li, M., Haas, B. W., Reuter, M., Bischoff, L., \& Montag, C. (2016). Similar personality patterns are associated with empathy in four different countries. Frontiers in psychology, 7 , 290. https://doi.org/10.3389/fpsyg.2016.00290

Muetia, R. (2016). The Association of Traits Personality and Pro-Social Behavior among Volunteers in Jakarta. Advanced Science Letters, 22(5-6), 1738-1741.

Penner, L. A., Dovidio, J. F., Piliavin, J. A., \& Schroeder, D. A. (2005). Prosocial behavior: Multilevel perspectives. Annu. Rev. Psychol., 56, 365-392.

https://doi.org/10.1146/annurev.psych.56.091103.070141

Pursell, G. R., Laursen, B., Rubin, K. H., Booth-LaForce, C., \& Rose-Krasnor, L. (2008). Gender differences in patterns of association between prosocial behavior, personality, and externalizing problems. Journal of Research in Personality, 42(2), 472-481. https://doi.org/10.1016/j.jrp.2007.06.003

Pisheh, H. F., Ahmadi, A., \& Naderi, G. (2014). Relation between Geography and Security in Rights of Islamic Republic of Iran. International Journal of Academic Research in Public Policy and Governace, 1(1), 30-40. 
Ritter, K., Dziobek, I., Preißler, S., Ruter, A., Vater, A., Fydrich, T., ... \& Roepke, S. (2011). Lack of empathy in patients with narcissistic personality disorder. Psychiatry research, 187(1-2), 241247. https://doi.org/10.1016/j.psychres.2010.09.013

Roberts, W., \& Strayer, J. (1996). Empathy, emotional expressiveness, and prosocial behavior. Child development, 67(2), 449-470. https://doi.org/10.1111/j.1467-8624.1996.tb01745.x

Shah, A. M., \& Rizvi, T. (2016). Prosocial behavior and big five-factor model of personality: A theoretical review. The International Journal of Indian Psychology, 4(1), 162-170.

Spreng, R. N., McKinnon, M. C., Mar, R. A., \& Levine, B. (2009). The Toronto Empathy Questionnaire: Scale development and initial validation of a factor-analytic solution to multiple empathy measures. Journal of personality assessment, 91(1), 62-71. https://doi.org/10.1080/00223890802484381

Song, Y., \& Shi, M. (2017). Associations between empathy and big five personality traits among Chinese undergraduate medical students. PloS one, 12(2), e0171665. https://doi.org/10.1371/journal.pone.0171665

Stormshak, E. A., Bierman, K. L., Bruschi, C., Dodge, K. A., \& Coie, J. D. (1999). The relation between behavior problems and peer preference in different classroom contexts. Child development, 70(1), 169-182. https://doi.org/10.1111/1467-8624.00013

Sze, J. A., Gyurak, A., Goodkind, M. S., \& Levenson, R. W. (2012). Greater emotional empathy and prosocial behavior in late life. Emotion, 12(5), 1129-1140. https://doi.org/10.1037/a0025011

Taylor, Z. E., Eisenberg, N., Spinrad, T. L., Eggum, N. D., \& Sulik, M. J. (2013). The relations of egoresiliency and emotion socialization to the development of empathy and prosocial behavior across early childhood. Emotion, 13(5), 822-831. https://doi.org/10.1037/a0032894

Telle, N. T., \& Pfister, H. R. (2016). Positive empathy and prosocial behavior: A neglected link. Emotion Review, 8(2), 154-163. https://doi.org/10.1177/1754073915586817

Thielmann, I., Spadaro, G., \& Balliet, D. (2020). Personality and prosocial behavior: A theoretical framework and meta-analysis. Psychological Bulletin, 146(1), 30-90. https://doi.org/10.1037/bul0000217 